\title{
Innovations in science popularization (in on-line legal texts)
}

\author{
Svetlana Pervukhina ${ }^{1, *}$ and Valintina Demchenko ${ }^{1}$ \\ ${ }^{1}$ Don State Technical University, 344003, Gagarina sq., 1, Rostov-na-Donu, Russia
}

\begin{abstract}
The article aims at analysis of popularization tactics as means of science popularization. The authors see these tactics as an innovative means of popularization of science and education development in the professional sphere. These tactics help specialists explain certain terms and concepts of a professional domain. As a research material, the authors chose on-line legal texts that are in demand for wide readership. The following tactics have been revealed: choosing sub-technical terms or spoke equivalents, using plain grammar structures and short understandable sentences, explication of professional presuppositions, quoting and referencing to the legal acts, using non-verbal elements. The authors used the National Corpus of the Russian Language for the comparison of the usage of professional terms and their spoken equivalents. The findings of the research can be used for linguistic and pragmatic simplification of legal texts (on-line and off-line), and professional texts of other professional domains. The findings of this research are essential for preparation of educational materials for higher professional institutions.
\end{abstract}

\section{Introduction}

The development of modern society is taking place thanks to the achievements of contemporary science in practical and theoretical terms. Society uses hi-tech devices that make life easier, as well as professional knowledge that also helps to solve certain kinds of problems. Scientists face the necessity to communicate their results to a broader audience outside academic areas [1]. The problem is that theoretical achievements of science are usually presented in a scientific language that is understandable only for professional scientists, but their findings should be put in a more simplified form for lay people who need them and/or might be interested in the scientific knowledge. It makes researches on popularizing science extremely valuable in both theoretical and practical aspects, prompting to tackle this task from different approaches. A pragmalinguistic approach seems to be rather promising for explanation how to adapt the professional technical vocabulary and texts for a new communicative situation with recipients having different professional background [2, 3, 4]. Popularization discourse is a type of communication when professional knowledge and the language describing this knowledge are simplified and/or transformed in an appropriate way.

\footnotetext{
*Corresponding author: s_pervuhina@mail.ru
} 
Studies of legal discourse and ways of effective communication between specialists and lay people were rather ample taking into account the domain peculiarities of communication [5], court discourse [6], translation problems in LSP [7] though they did not pay so much attention to different strategies of on-line legal discourse. The previous researches concentrated mostly on popularization strategies in medical discourse and medical blogs [8] but did not investigate the question on legal blogs and on-line consultations.

In modern scientific literature, popularization discourse is described quite insufficiently; the main communicative strategies and tactics of popularization discourse are shown little. The objective of this study is to describe the strategies and tactics that serve to popularize scientific knowledge on-line.

\section{Method}

The popularization discourse includes consultations of clients with lawyers in their legal practice. So, we analyzed on-line consultations on popular sites https://pravoved.ru/, https://pravo.rg.ru, https://jurysti.ru. We chose these sites because they include two types of science popularization: the first one includes simplified texts of laws explained for lay people, and the second type is a chat between lawyers and people who needed legal help and asked a definite practical question. Actually, these two types of communication present different models of popularization - non-personalized and personalized. In the first case of a non-personalized communication, the recipient is an abstract model of a layman who might need this knowledge and / or might be interested in such a question. In this case, a sender of the message, the author who popularizes the scientific knowledge, addresses a potential lay audience and does not take into account any definite problem, the advice is hypothetical. In the second case of personalized communication a group of professionals are trying to solve a problem of a layman that has been described in the question. It is an example situation where specialists communicate with a definite person.

The second step of our research included comparison of the popularization articles with legal codes in order to find out popularization strategies. We found the references on the legal codes in the analyzed articles and compared the texts of these codes with their explanations and interpretations in the consultation articles. We searched for varieties in vocabulary choice, style transformations, and explication of professional presuppositions. We also paid attention to the ways of presenting the scientific knowledge including verbal and non-verbal elements, choice of technical, sub-technical and non-technical vocabulary, explanation strategies. To distinguish between technical, sub-technical and non-technical vocabulary we used National Corpus of the Russian Language (NCRL) (ruscorpora.ru).

The third step of our investigation included analyses of lawyers' replies to the laymen's questions about legal problems. We used the same sites of on-line legal advice. On this step we were interested in ways of activation of professional knowledge either through definite quotations of legal codes or through presuppositions. We distinguished different ways of popularizing scientific knowledge while communicating on legal questions in popularizing articles and in dialogues with possible clients.

The forth step of our research included distinguishing different strategies of popularizing discourse in on-line legal texts. We analyzed strategies in two different situations of communications: one-to-many when a specialist explains legal questions in an article, and one-to-one when a client asks a question for the specialists to answer.

\section{Results}


In legal discourse, people deal with legal documents organizing and systemizing the legal system that constitute judicial discourse. Understanding these texts, moreover, acting in accordance with them and making choices considering them is not a simple task. That is the reason why interpreting law is such an important issue. The popularization process is strongly connected with text transformations for the sake of recipients, considering their background knowledge [5], linguistic and terminology competence, and their interest in the topic described. Legal texts with strong explanatory power aim to popularize scientific knowledge that may be of interest to a non-specialist in this field or practically used for solving a problem. The texts of articles and consultations which we analyzed are adapted texts of Codes and Ordinances (i.e. professional texts), which can be classified as texts belonging to popularization discourse.

\subsection{Vocabulary choice}

The Internet became a prolific ground for popularization as a whole. Legal discourse is a vivid example. Evidently, a consumer does not always turn for legal advice to a lawyer directly, but tries to find a suitable solution browsing articles in the Internet or sections of on-line advice. In these articles and columns, one can find practical tips to help solve the consumer's problems. We found out evident differences between legal language of official law and popularization articles. The vocabulary choice showed a tendency to a spoken language. For example, the term 'mesto prebyvaniya' (place of residence) was changed to an everyday expression 'mesto zhiteljstva' (address) which is more common. A legal notion 'otpusk po beremennosti i rodam' (maternity leave) was replaced by an everyday word 'dekret' that is not used in Russian legislation at all.

The results of popularizing word choice are given below in Tab. 1. We searched for entries of terms and their spoken equivalents in general corpus of NCRL. The findings show that, as a rule, equivalents are more common in the texts of general corpus, for the exception of made-up expressions ('nalogovyj vznos'). The official legislation uses the subtechnical term 'nalog' (tax) or 'strakhovoj vznos' (insurance fee). The expression 'nalogovyj vznos' was made up in the context of explanation of the professional situation through the motivation of words 'nalogovyj' and 'vznos' that are well-known to lay audience.

Table 1. Terms and their equivalents in popularizing on-line legal texts

\begin{tabular}{|c|c|c|c|}
\hline Term & Entries in NCRL & Equivalent & Entries in NCRL \\
\hline $\begin{array}{c}\text { Nalog } \\
\text { tax }\end{array}$ & 1267 & $\begin{array}{c}\text { Nalogovyj vznos } \\
\text { Taxing fee }\end{array}$ & 1 \\
\hline $\begin{array}{c}\text { mesto prebyvaniya } \\
\text { place of residence }\end{array}$ & 53 & $\begin{array}{c}\text { mesto zhiteljstva } \\
\text { address }\end{array}$ & 403 \\
\hline $\begin{array}{c}\text { otpuskpo } \\
\text { beremennosti } i \\
\begin{array}{c}\text { rodam } \\
\text { maternity leave }\end{array}\end{array}$ & 0 & dekret & 27 \\
\hline
\end{tabular}

'Otpusk po beremennosti i rodam' is a technical term for it is used only in a professional domain of the legal sphere. 'Nalog' is a sub-technical term that is used both in a professional domain and a spoken language. The corpus data show it in Tab.1.

Professional discourse is distinguished by the use of special concepts and terms depending on the format of communication and the difference in participants' background professional knowledge. A common format of professional communication is "specialist specialist". It implies that both the addressor and the recipient have special presuppositions that make up scientific or professional knowledge in a particular area. Professional 
discourse includes both the structure of knowledge (in the form of concepts, frames, constructs, etc.) and ways of using them (operating with knowledge to solve professional problems). In an ideal model it might seem that specialists understand each other pretty well in their professional domain, but it is not always so. The findings of P. John et.al. [3] show that linguistic competence is as important as professional knowledge. Our investigation revealed a lot of sub-technical terminology in popularizing articles. Subtechnical terminology is vocabulary that is used in a professional domain and belongs to a spoken language. That means that in adapting a professional text for lay audience a basic linguistic competence was employed. The addressors tended to use sub-technical terminology in order to employ mutual knowledge. As it is explained in [4], mutual knowledge is something held as true with great certainty, since it is gained from personal rather than second-hand experience. In this case, the individual usually knows for sure that his or her interlocutor also knows it.

In a lot of professional domains, communication between specialists and lay audience is quite common. The dyad of the terms "specialist - layman" implies the divergence of background knowledge, skills, and qualifications in the same professional area. One and the same person can be a "specialist" in one professional area and a "layman" in the other areas. Thus, the study of the characteristics of professional discourse and its popularization finds a wide sphere of application.

\subsection{Style transformation}

Syntax of legal language and its complexity has been studied by a lot of researches [9, 10]. A lot of archaic expressions are used in the legal contracts and laws due to the tradition; they belong exclusively to legal sphere and may cause misunderstanding. So, while popularizing legal texts, the authors try to use more natural language. They use short sentences, leading questions and personalization. Let us give some examples to illustrate this statement:

"Today, when society is subordinated to market relations, each of us acts either as a party that offers services / goods, or as those who buy it. However, there are different situations in life! Sometimes spending money on a service, you may get absolutely nothing in return. What to do in such cases? Let's take a closer look" (https://jurysti.ru/vozvratdeneg-za-neokazannuyu-uslugu/).

This extract is written in the newspaper style that is more common for lay audience. It has short sentences with plain syntax (rare subordinate clauses, verbal structures, etc.). The exclamatory sentence serves to attract the reader's attention. The rhetorical question creates personalization by modeling a dialogue with the reader.

\subsection{Explication of professional presuppositions}

Professional knowledge is a key hindrance in understanding professional texts for lay audience. In [11] it is described how to make databases for professional knowledge and terms. In popularization of scientific knowledge the same strategies are widely used and seem to be rather successful. That happens because the most important information for readers is rendered not only through equivalents of terms but through explanation of professional knowledge and procedure of professional actions.

Usually, the reader is searching for advice on what to do and explanations of a legal case he or she faces. Let us give an example of how the presupposition is explicated:

"Remember that your rights are protected by the state and are explicated and fixed in the Consumer Protection Law, which was adopted back in 1992. It fixes the terms of 
interaction between service customers and those who perform them, so that in the end no one is left at a loss" (https://jurysti.ru/vozvrat-deneg-za-neokazannuyu-uslugu/).

This quotation includes the statement of the legislative act that regulates this situation (The Consumer Protection Law) and states the date of creation of this law. The early date gives the information about a long period of practice of this law.

\subsection{Non-verbal elements}

On-line legal discourse has features of media discourse that are revealed in style, as has been mentioned above, and visual elements are often used there. To attract the reader's attention, the addressor may exploit non-verbal information. Fig.1 and Fig.2 are illustrations to the articles on legal issues. Fig. 1 illustrates the article with the headline "IS the maternity leave included in labour experience?" The article is about calculation of labour experience and it sheds light on the question if the time of taking care of the child can be considered as labour experience.

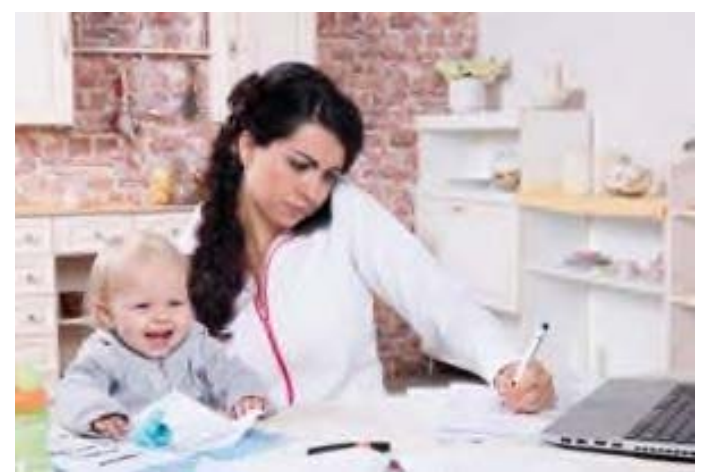

Fig. 1. Illustration to the article with the headline "Is the maternity leave included in labour experience?" https://jurysti.ru/vhodit-li-dekret-v-trudovoj-stazh/

The picture demonstrates a mother with the child on her lap and simultaneously talking on the phone, working with the computer and taking notes. The picture is metaphoric: the woman is doing several things at the same time, and the legislation considers this period of woman's life as the time included in labour experience. This picture serves for drawing attention to the multi-tasking aspect of the situation.

Fig. 2 shows a man tearing some lists of paper, evidently documents. His suit refers to business context; his face expression reflects anger and disgust. As in the previous example, it shows connotative senses of the article - as a rule, annihilation of a labour contract is connected with negative emotions of the employee. The article also describes situations with void contracts, so the non-verbal element repeats factual and connotative verbal information of the article. 


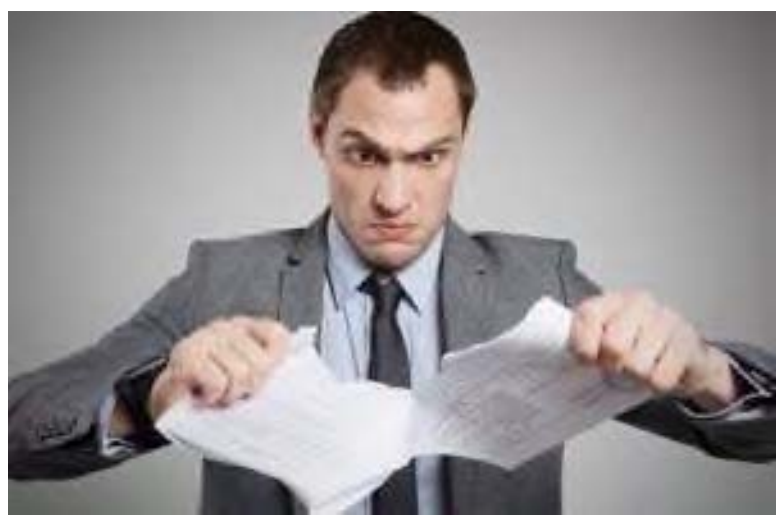

Fig.2. Illustration to the article with the headline "Annihilating of labour contract" https://jurysti.ru/annulirovanie-trudovogo-dogovora/

The visual elements in popularization articles serve for attraction of attention to the article and for rendering factual and connotative senses.

\section{Analysis}

\subsection{Popularization strategies}

We were interested in on-line consultations with lawyers in search of innovative ways to popularize science. Such sites are of paramount practical importance for lay audience. Since the genre of consultation is carried out in the "specialist-layman" mode, we observed popularized texts and the ways used to put complicated professional texts into more comprehensible form.

The popularized texts are secondary texts which means they are built on the basis of a primary professional text. The primary text reflects the world or its notions and structures of knowledge kept in a human mind. In our case, the professional primary texts organize state legal structure, legal laws, and legal relations of people. Communicative popularizing strategies are used to convey professional knowledge, describe specific professional concepts, processes, etc.

In legal discourse, some communication situations imply inequality of communicants in terms of their knowledge and skills in the professional - legal - sphere [12]. Communication in legal discourse from the angle of science popularization can be presented as the interaction of the legislative system and the everyday experience. Everyday life experience is used to explain the situations, terms and actions of the professional domain. We illustrated this situation through vocabulary choice (tendency to use spoken equivalents rather than terms), style transformation (human-like approach), and explicitly giving information about professional knowledge.

In the legal domain, there are face-to-face (oral) legal consultations and on-line consultations in the form of a question-answer. There is a distinction in on-line communication, stating one-to-one communication, one-to-many interaction, and intergroup discussions [13]. In legal popularization discourse we managed to find one-toone and one-to-many communication. Some legal sites underline the advantage of the latter model of communication where a non-specialist's question or problem is dealt with by a number of specialists so that the consumer may have the possibility to choose the most appropriate advice in this case. The specialist helps to find the best solution to the problem through the adaptation of legislation for a non-specialist client, as well as for all readers of 
this site. Thus, sites with expert advice perform an educational or popularizing function. Several communicative tactics are noted that are used in the genre of online legal advice:

Tactic 1. Quoting a legislative act (law);

Tactic 2. Reference to the law;

Tactic 3. Interpretation using equivalents of terms to describe legal actions to be done.

A communication popularization strategy consists of various combinations of the above tactics. The choice of tactics and their sequence depend on the situation, as in this example:

"The status of an individual entrepreneur involves the use of a tax on professional income, but it cannot be combined with other tax regimes. Federal Law of 27.11.2018 N 422-FZ "On conducting an experiment to establish a special tax regime" Tax on professional income". Article 5. Procedure and conditions for the beginning and termination of the application of a special tax regime ... [The author further cites Article 5 in full]" (Pravoved.ru).

In some cases, the situation is first explained through everyday concepts (Tactic 3), and then quotation tactic (Tactic 1) is used to confirm their advice. The quotation and reference are important from the practical point of view: the quotations import context, they underline the legislative origin of the speech act [14]. Still, it is the official legislation that regulates the relations between persons and entities. As it has been noted before in [14], quotations refer to a prior contexts that have a scientific or professional origin. Interpretation with the spoken equivalents is essential for this is the common ground for specialists and lay audience.

Below is an example of Tactic 2 that is a reference to a legislative act:

"If the service provider refuses to provide the consumer with benefits, they will be brought to administrative responsibility in the form of a fine in accordance with Part 3 of Art. 14.8 of the Administrative Code of the Russian Federation"(Pravoved.ru).

Here is presented a speech act with the perlocutionary force based on the tactics of referring to a legislative act. The author of the popularizing text explicates the presupposition of the knowledge of the Code of Administrative Offenses of the Russian Federation, providing information on the consequences of non-compliance with this legislative act. In our example it is done with the reference to a legal article. A reference differs from a quotation in the way it addresses the information - while the quotation is a connection with a prior discourse, the reference is a reminder of the necessary legislative act. It has a smaller explanatory power for a lay person, who would need to consult the law to understand the commentary of the writer. Still the reference can be useful as a compressed form of legal advice.

A lot of on-line consultation sites are run by a team of lawyers, and a great number of professionals may answer a question using different tactics. In some cases only references are given; though the answer is brief, the recipient might need to consult the prior text of the law. In some cases there is a quotation of the law and its explanation in spoken equivalents. The latter popularization strategy is seen to be the most effective.

The analyzed examples show that within the framework of legal discourse, a specialist's consultation is based on legislative texts and on the legislative system as a whole, with all the interrelationships of specific professional concepts. Within the framework of legal discourse, the specialist relies on the base of legal knowledge, which they received in their professional education and work experience. Here is an example of a reference to laws:

"The main regulatory legal acts that regulate relations between spouses arising in the distribution of debts are: Civil Code of the Russian Federation. RF IC. Federal Law "On Mortgage (Pledge of Real Estate)" dated July 16, 1998, No. 102-FZ (hereinafter - Law No. 102-FZ) "(Pravoved.ru).

The editor explains in what source it is possible to clarify this issue in more detail and gives a reference to this source. The legislative document provides all the details of situations of operation of the law, which often violates the maximum information sufficiency according to P. Grice. At the same time, a specific situation, described in 
everyday terms, appears in the secondary adapted text, and the adapter provides the required amount of information without unnecessary details that can confuse a layman. Interpretation of the situation, if necessary, involves the mechanism of explication of presuppositions, as in the following example:

"The Ministry of Construction of the Russian Federation has developed an approximate form of receipt for utility services. This is due to the fact that since January 1, 2017, services for general house needs have moved from the category of communal services to housing services "(Pravoved.ru).

The author refers to the changes in legislation to explain the reasons for changing the forms of payment, which worries the reader.

Summarizing what has been said, we note that tactics in the genre of consultation are aimed at the use of everyday vocabulary, i.e. vocabulary, which is sure to be known to the reader. They also rely on the everyday experience of the addressee.

\section{Discussion}

Science popularization is an extremely important issue for education. The amount of knowledge that the Internet provides is truly overwhelming. The knowledge that should be attained while acquiring a profession at a higher educational establishment is enormous as well. Our research offers the way how to simplify the knowledge and how to structure the knowledge for the readers who have neither special education nor special training. Our findings can be applied in the educational context of the legal sphere as well as any other sphere that needs simplification and adaptation of information. Educational environment naturally exists for the sake of transmitting knowledge from researchers (or specialists) to students (non-specialists).

In the case of science popularization, we are talking about the author's efforts aimed at transforming a professional text into one that would be understandable to lay people, and they could use it for their practical purposes.

Our research has been done in the sphere of semiotics. Semiotics deals with three aspects while considering signs: semantics, syntactics, and pragmatics. Semantics studies the relationship between the notion and how it is signified; syntactics deals with the relationship of signs; and pragmatics considers the relationship between a sign and the person who uses it. Popularization of science is connected with all three aspects. As our research has shown, the effective way to simplify a professional text is to choose appropriate signs in proper situations of communication taking into account the recipient's background knowledge.

This investigation takes into account the speech activity of the specialist and a lay person in speech communication in a certain communication situation where the background knowledge of the participants is not equal. This semiotic approach allows viewing the text from the semantic content of linguistic signs and their paradigmatic relationships, the syntactic organization of linguistic signs in the text and their syntagmatic relations, and, finally, the pragmatic dependence of the sender's choice of speech signs [15]. Science popularization implies precisely a change in the mental state of the reader due to the emotions that arise when s/he meets the well-known lexemes, for which the reader has already formed positive emotions.

Different discourses evoke different emotions in readers related to the complexity of the text: inaccessibility of information can cause irritation, anger, boredom, etc. For example, professional discourses will cause negative emotions among non-professionals, since they are filled with unfamiliar signs (terminology), incomprehensible syntactic statements, and finally, incomprehensible topics. Therefore, we investigated the structure of professional discourse and innovative strategies of science popularization. One of the innovative strategies is adaptation of scientific texts, so that they can become a part of reader's 
conceptual sphere. The conceptual sphere is the knowledge, beliefs and experience of the reader that are organized so that $\mathrm{s} / \mathrm{he}$ can understand new information. Every branch of science is accumulating new knowledge at extremely high speed, and effective strategies for popularization of science are called for.

\section{Conclusion}

There are a number of communication tactics that can be called tactics for science popularization in the analysis of pragmalinguistic communication strategies. In our case, these include the following: text simplification (using short structures and spoken equivalents of terms), text compression (omitting redundant information in the new situation of communication), text extension (explicating professional presuppositions), text polycoding (using non-verbal components to replace certain verbal information).

The popularizing strategy for on-line legal texts includes tactics for describing everyday situations, using everyday vocabulary, and quoting and referencing to the law. The tactics of text extension leads to the explication of professional knowledge and assumptions due to the provision of new information for the lay addressee. In all the cases, communication strategies in popularization of science select information that is important and relevant to the addressee. The degree of importance and relevance of information is determined by the goals of communication and the volume of professional knowledge of the addressee.

\section{References}

1. D. Banks, E. Di Martino, Introduction: Linguistic and discourse issues in contemporary scientific communication. Aspects of communicating science to a variety of audiences. Journal of Pragmatics, 139, 185-189 (2019) doi:10.1016/j.pragma.2018.10.011

2. S. Ni, K. K. Sin, A matrix of legislative speech acts for Chinese and British statutes. Journal of Pragmatics, 43(1), 375-384 (2011) doi:10.1016/j.pragma.2010.07.012

3. P. John, B. Brooks, U. Schriever, Speech acts in professional maritime discourse: A pragmatic risk analysis of bridge team communication directives and commissives in full-mission simulation. Journal of Pragmatics, 140, 12-21 (2019) doi:10.1016/j.pragma.2018.11.013

4. B. P. H. Lee, Mutual knowledge, background knowledge and shared beliefs: Their roles in establishing common ground. Journal of Pragmatics, 33(1), 21-44 (2001) doi:10.1016/s0378-2166(99)00128-9

5. J. Engberg, Knowledge construction and legal discourse: The interdependence of perspective and visibility of characteristics. Journal of Pragmatics, 42(1), 48-63 (2010)doi:10.1016/j.pragma.2009.05.011

6. Y. Ge, H. Wang, Understanding the discourse of Chinese civil trials: The perspective of Critical Genre Analysis. Journal of Pragmatics, 152, 1-12 (2019) doi:10.1016/j.pragma.2019.07.024

7. A. Matulewska, Legal and LSP Linguistics and Translation: Asian Languages' Perspectives. International Journal of Semiotics of Law, 32, 1-11 (2019) doi: 10.1007/s11196-019-09602-x

8. M. Sokół, "Have you wondered why sportspeople die?" The medical weblog as a popularisation tool. Discourse, Context \& Media, 25, 13-24 (2018) doi:10.1016/j.dcm.2018.07.004 
9. V. V. Stepanova, Translation Strategies of Legal Texts (English-Russian). Procedia Social and Behavioral Sciences, 237, 1329-1336 (2017) doi:10.1016/j.sbspro.2017.02.218

10. L. V. Bartley, Book review. Journal of Pragmatics, 139, 129-131 (2019) doi:10.1016/j.pragma.2018.11.007

11. A. Reimerink, Q. M. García de, S. Montero-Martínez, Contextual information in terminological knowledge bases: A multimodal approach. Journal of Pragmatics, 42(7), 1928-1950 (2010) doi:10.1016/j.pragma.2009.12.008

12. S. V. Pervukhina, Characteristic features of adapted legal text. Language and Culture. 1(5), 20-24 (2015) doi: 10.17223/24109266/5/3

13. M. Dynel, Participation framework underlying YouTube interaction. Journal of Pragmatics, 73, 37-52 (2014) doi:10.1016/j.pragma.2014.04.001

14. A. Fetzer, "And I quote": Forms and functions of quotations in Prime Minister's questions. Journal of Pragmatics, 157, 89-100 (2019) doi:10.1016/j.pragma.2019.05.004

15. G. G. Matveeva, I. A. Zyubina, Written text: approaches to identifying implicit pragmatics. Vestnik of Volgograd State University. Series 2. Linguistics, 17(2), 26-32 (2018) https://doi.org/10.15688/jvolsu2.2018.2.3 